\title{
A Comprehensive Method for Subsidence Prediction on Two-Seam Longwall Mining
}

\author{
Bin Zhang ${ }^{1,2, *}$, Jiacheng $\mathrm{Ye}^{1,2}$, Zhongjian Zhang ${ }^{1,2}$, Liang $\mathrm{Xu}{ }^{1,2}$ and Nengxiong $\mathrm{Xu}{ }^{1,2}$ \\ 1 School of Engineering and Technology, China University of Geosciences (Beijing), Beijing 100083, China \\ 2 Key Laboratory of Deep Geodrilling Technology, Ministry of Natural Resources, Beijing 100083, China \\ * Correspondence: sc_zhb@cugb.edu.cn; Tel.: +86-131-2670-2993
}

Received: 14 July 2019; Accepted: 12 August 2019; Published: 15 August 2019

\begin{abstract}
The purpose of mining subsidence prediction is to establish a reliable assessment for surface subsidence resulting from underground mining. In this study, a new method for predicting subsidence in two-seam mining is proposed. First, the surface subsidence due to mining the upper seam is monitored. Then, taking the subsidence data as indicators, the optimal mechanical parameters of overlying strata can be obtained by orthogonal experimental design and inverse analysis of numerical simulation. Finally, further subsidence is calculated and predicted by the numerical model. A case of two-seam underground mining is studied using this methodology. This coal mine is located in the Dongsheng coal field in Inner Mongolia, China. Based on GPS surface subsidence monitoring and parameter inversion, the subsidence induced by two-seam mining is estimated and predicted. This study shows that the ratio of the height of overlying strata to mining thickness $(\mathrm{H} / \mathrm{M})$, mining configuration and adjacent mining have a significant effect on the surface subsidence caused by two-seam mining. By parameter inversion, the proposed optimal parameters can be applied to predict the subsidence of a nearby mine with similar stratigraphic conditions. Furthermore, this methodology can also be used to predict the subsidence caused by mining of more than two seams.
\end{abstract}

Keywords: underground mining; two-seam mining; surface subsidence; orthogonal experimental design; parameter inversion

\section{Introduction}

In the last decade, China accounted for $40 \%$ of worldwide coal production. Moreover, the coal production of Inner Mongolia has reached one billion tons per year, gradually increasing to $25 \%$ of China's production. However, surface subsidence induced by underground mining can cause a series of geological environmental issues [1-4]. Due to longwall mining methods, the scope of subsidence is increasing year by year, and deterioration of the environment, destruction of natural landscapes, grassland degradation, and desertification are also expanding in Inner Mongolia. Therefore, it is essential to establish a reliable subsidence prediction method for longwall mining.

Currently, subsidence prediction in single-seam mining mainly uses empirical methods, numerical modeling methods (e.g., finite element methods, finite difference methods, discrete element methods), physical modeling methods, and theoretical analysis methods (e.g., influence function methods, profile function methods) [5-17].

Due to limited coal resources, multiseam mining has become inevitable. However, conventional single-seam subsidence-prediction methods are inaccurate in predicting multiseam subsidence $[18,19]$. This is due to the differences in profile, shape and magnitude of multiseam subsidence in comparison with that of single-seam subsidence [20,21]. The empirical method puts great effort into subsidence prediction because of the lack of theoretical analysis and individual difference; the numerical modeling methods and theoretical analysis have great advantages in explaining the deformation mechanism. 
However, generally speaking, there are many indeterminate aspects in accurately obtaining the parameters of strata, which raises difficulties for these methods; physical modeling methods are able to explain the mechanism of subsidence, but it is difficult to predict further deformation because of the difference in size between the physical model and actual engineering.

To daste, most scholars have studied multiseam subsidence by discrete influence function methods, numerical modeling methods and physical modeling methods [22-25]. Ren et al. [22] predicted multiseam subsidence of a complicated case in Australia by using the generalized influence function method (GIFM). This method was expected to be applied in areas with similar geological and mining conditions. Adhikary et al. [19] evaluated the utility of 2D and 3D numerical simulation in multiseam subsidence prediction. Ghabraie et al. [21] predicted the subsidence of two-seam mining by the 3D finite element analysis method. Ghabraie et al. [26] studied the differences between the single-seam and multiseam subsidence parameters and proposed an improved influence function to predict the subsidence of multiseam mining. Ghabraie et al. [25] used a gravel physical multiseam model to simulate the effect of different longwall mining methods on surface subsidence. Jung et al. [14] selected propensity and dip as two important considerations and used a settlement sensitivity prediction method to predict the ground subsidence of coal mines with complex conditions and irregular shape. Thongprapha et al. [16] used a physical model to simulate the effects of underground cavern excavation on surface subsidence under supercritical conditions and concluded that the geometry of underground caverns is the main factor controlling land subsidence. Current research used conventional methods to study the subsidence and its effect factors, including depth, shape, exploitation method and so on. Because of the limitation of these methods, larger effort exits.

The Yangjiacun coal mine in the Dongsheng coal field of Inner Mongolia, China, was studied to introduce a new method of two-seam subsidence prediction, which is realized on the basis of subsidence monitoring, parameter inversion and numerical simulation. In this method, first, the surface subsidence induced by mining the upper seam is monitored with GPS, total station and level. Then, based on the strata parameters obtained from laboratory tests, the orthogonal experimental design is used to inverse the optimal mechanical parameters of overlying strata by taking the subsidence data as indicators. Finally, the optimal parameters for predicting further subsidence by numerical simulation are adopted. This method could provide a significative measure for the subsidence prediction of two-seam longwall mining and be referred by analogous engineering.

\section{Methodology}

The subsidence prediction method for two-seam mining proposed in this study includes three main segments (as shown in Figure 1): (1) surface subsidence monitoring, (2) parameter inversion of the strata overlying the upper seam, and (3) subsidence prediction for two-seam mining.

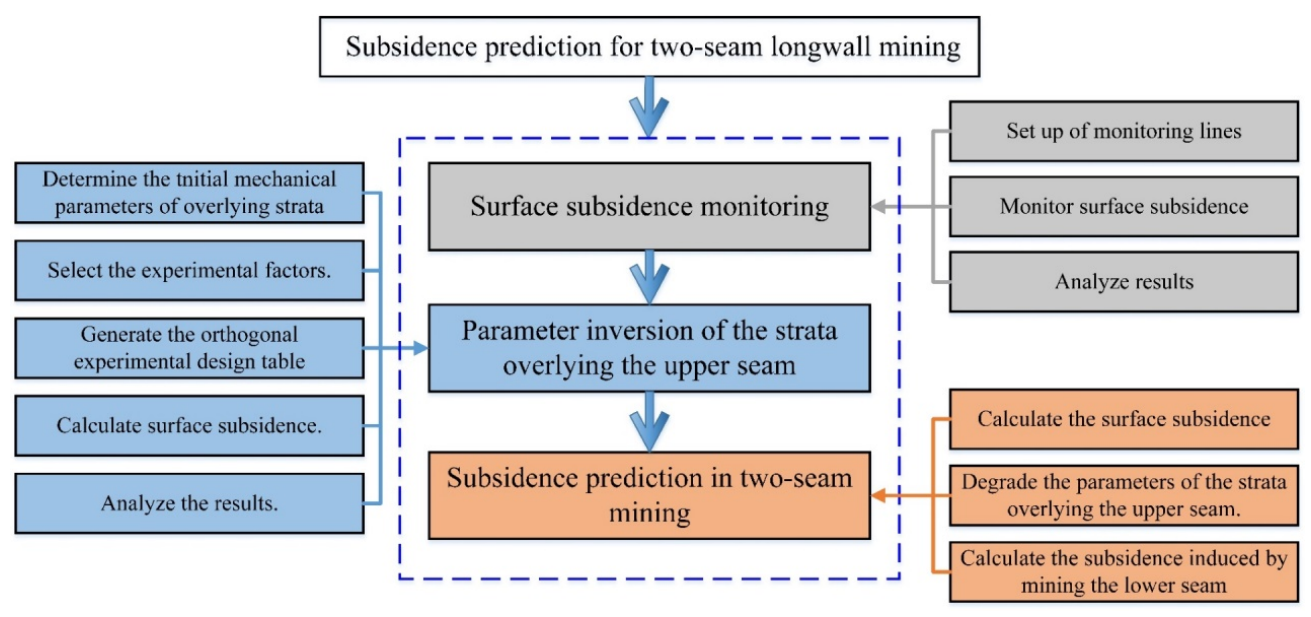

Figure 1. Flow chart of the subsidence prediction method. 


\subsection{Surface Subsidence Monitoring}

To monitor surface subsidence, the monitoring station must be set up before mining. Surface subsidence monitoring can be realized by GPS, total station and level. The monitoring includes the following three main steps:

(1) Set up the monitoring lines. The layout of monitoring lines is generally composed of two crossed lines. One extends along the mining direction of the coal seam, and the other runs perpendicular to the mining direction. Each monitoring line is mainly composed of the control points and monitoring points. The control points are established far from the subsidence area, so they are stable and reliable. The monitoring points are set within the subsidence area.

(2) Monitor surface subsidence. This step mainly consists of measuring the elevation of the monitoring points. The monitoring generally proceeds for longer than one year. The measurement is carried out every 7-10 days. For monitoring points with large subsidence, the measurement frequency should be increased. It can be considered that the entire subsidence of underground mining is completed if the subsidence of each monitoring point increases by less than $30 \mathrm{~mm}$ every 6 months.

(3) Analyze result. The mining subsidence can be obtained by calculating the difference of elevation data measured before and after mining.

\subsection{Parameter Inversion of the Strata Overlying the Upper Seam}

Generally, the mechanical parameters of strata are determined by laboratory tests. However, because the rock masses are composed of intact rocks and discontinuities, the mechanical parameters of intact rocks obtained by laboratory tests are quite different from those of the rock masses [27-29]. However, some researchers have indicated that the mechanical parameters of overlying strata can be obtained by the method of parameter inversion $[30,31]$. The parameter inversion is achieved by orthogonal experimental design and inverse analysis of numerical simulation. The main six steps are as follows:

(1) Determine the initial mechanical parameters of overlying strata. The initial mechanical parameters can be determined by laboratory tests, including tests for density $(\rho)$, tensile strength $\left(\sigma_{t}\right)$, compressive strength $\left(\sigma_{b c}\right)$, modulus of elasticity $(E)$, Poisson's ratio $(\mu)$, cohesion force (c), and angle of internal friction $(\varphi)$.

(2) Select the experimental factors. The Mohr-Coulomb yielding criterion, which is adopted in this study, can reasonably predict large strata deformation induced by coal-seam mining [21]. Four parameters are considered in this criterion, $\mathrm{E}, \mu, \mathrm{c}$ and $\varphi$, which are chosen as the experimental factors.

(3) Select the experimental indicator. The ratio of average surface subsidence (RASS) is defined as the ratio of the average subsidence obtained by monitoring to the average subsidence obtained by numerical simulation. The RASS is adopted as the experimental indicators in this study because it is not susceptible to changes in strata parameters and it can also be obtained in other specific ways, such as field measurement.

(4) Generate the orthogonal experimental design table. An orthogonal experimental design table with multiple factors and multiple levels is established according to the orthogonal experimental design theory. The multiple factors refer to the 4 experimental factors (i.e., E, $\mu, \mathrm{c}$ and $\varphi$ ), and multiple levels mean that each experimental factor will have different gradients.

(5) Calculate surface subsidence. First, establish the 3D geology model. Second, assign the 4 experimental factors (i.e., $\mathrm{E}, \mu, \mathrm{c}$ and $\varphi$ ) obtained from different schemes of the orthogonal experimental design table to the numerical model. Finally, calculate the surface subsidence to obtain the RASS of each scheme. During the numerical simulation, factors such as boundary conditions and mesh size are all the same, and only the 4 experimental factors (i.e., E, $\mu, \mathrm{c}$ and $\varphi$ ) will change according to the different schemes. 
(6) Analyze the results. When the RASS is closer to 1, the result of this simulation scheme is closer to reality. After comparing the RASS results of different schemes, the factors of the scheme whose RASS is closest to 1 are selected as the optimal parameters of the overlying strata.

\subsection{Subsidence Prediction in Two-Seam Mining}

Based on the optimal mechanical parameters of the strata overlying the upper seam proposed by parameter inversion, the two-seam subsidence can be predicted by numerical simulation. The main steps are as follows:

(1) Calculate the surface subsidence induced by mining the upper seam $\left(\mathrm{S}_{1}\right)$ through numerical simulation.

(2) Degrade the parameters of the strata overlying the upper seam. The stress state of the rock overlying the upper seam will redistribute after the mining of the upper seam. The rock will yield if the stress exceeds its strength. Therefore, it is necessary to carry out the parameter degradation of the yielded rock when calculating the subsidence induced by mining the lower seam. In this study, when carrying out the numerical simulation in FLAC ${ }^{3 \mathrm{D}} 5.0$ (V5.0, Itasca, Minnesota, USA), the $\mathrm{E}$ of yielded rock is reduced by $99.5 \%$, while other parameters are unchanged, according to Ghabraie et al. [21]; the corresponding code is provided in Supplementary Materials.

(3) Calculate the subsidence induced by mining the lower seam $\left(\mathrm{S}_{2}\right)$. By assigning the degraded parameters to the numerical model, $S_{2}$ can be calculated. Then, by adding the former subsidence $\left(S_{1}\right)$, the final subsidence induced by two-seam mining (S) can be defined as $S=S_{1}+S_{2}$.

\section{Case Study}

\subsection{Geology and Mining History of the Site}

The Dongsheng Coal Field is located in Ordos City in Inner Mongolia (as shown in Figure 2). It has 2236 million tons of coal reserves. According to the work report of the Ordos City Government in 2017, the annual coal production of the Dongsheng Coal Field reached 61.31 million tons. The main coal-bearing strata are part of the middle and lower Yan'an formation, which was deposited during the Jurassic period. The main coal-bearing strata consist of 6 coal groups and 23 minable coal seams; the 2-1, 2-2, 3-1, 4-1, 4-2, 5-1, 6-1 and 6-2 coal seams are the main minable coal seams. There are no faults or incursive magmatite within the mining area. The dip angle of the coal seams is 1 to $3^{\circ}$, and the thickness is 1 to $7 \mathrm{~m}$. The average depth of the coal seam is 100 to $300 \mathrm{~m}$. The ratio of the height of the overlying strata to mining thickness (H/M) ranges from 4-110 and is generally smaller than 50 in this area [32]. Therefore, coal mining will easily cause substantial surface subsidence. By the end of 2013, the total surface subsidence area in the Dongsheng Coal Field was more than $117.7 \mathrm{~km}^{2}$, which accounted for approximately $57 \%$ of the Inner Mongolia subsidence area.

The Yangjiacun Coal Mine is located in the middle of the Dongsheng Coal Field (as shown in Figure 2). The coal reserve is 976.82 million tons, and the available reserve based on mine design is 441.82 million tons. The expected mining capacity is 5.0 million tons per year, and the service life is 63.3 years. The main minable coal seams of the Yangjiacun Coal Mine are the 2-2 and 4-1 coal seams. The average thickness of the $2-2$ coal seam is $7.0 \mathrm{~m}$, and the average depth is $165 \mathrm{~m}$. The average thickness of the 4-1 coal seam is $5.0 \mathrm{~m}$, and the average depth is $218 \mathrm{~m}$. The stratigraphic section is shown in Figure 3. Yangjiacun Coal Mine was built in November 2008 and started mining in May 2011. All coal mining adopted the longwall mining method and the forced roof caving method.

The 2-2 coal seam in Yangiacun Coal Mine has 6 panels, which correspond with panels No. 222201-222206 from east to west; the 4-1 coal seam also has 6 panels, which correspond with panels No. 414101-414106 from east to west. The distances between adjacent panels vary from 18 to $25 \mathrm{~m}$. The layout of the panels is shown in Figure 4. The dimensions of the panels are shown in Table 1. 


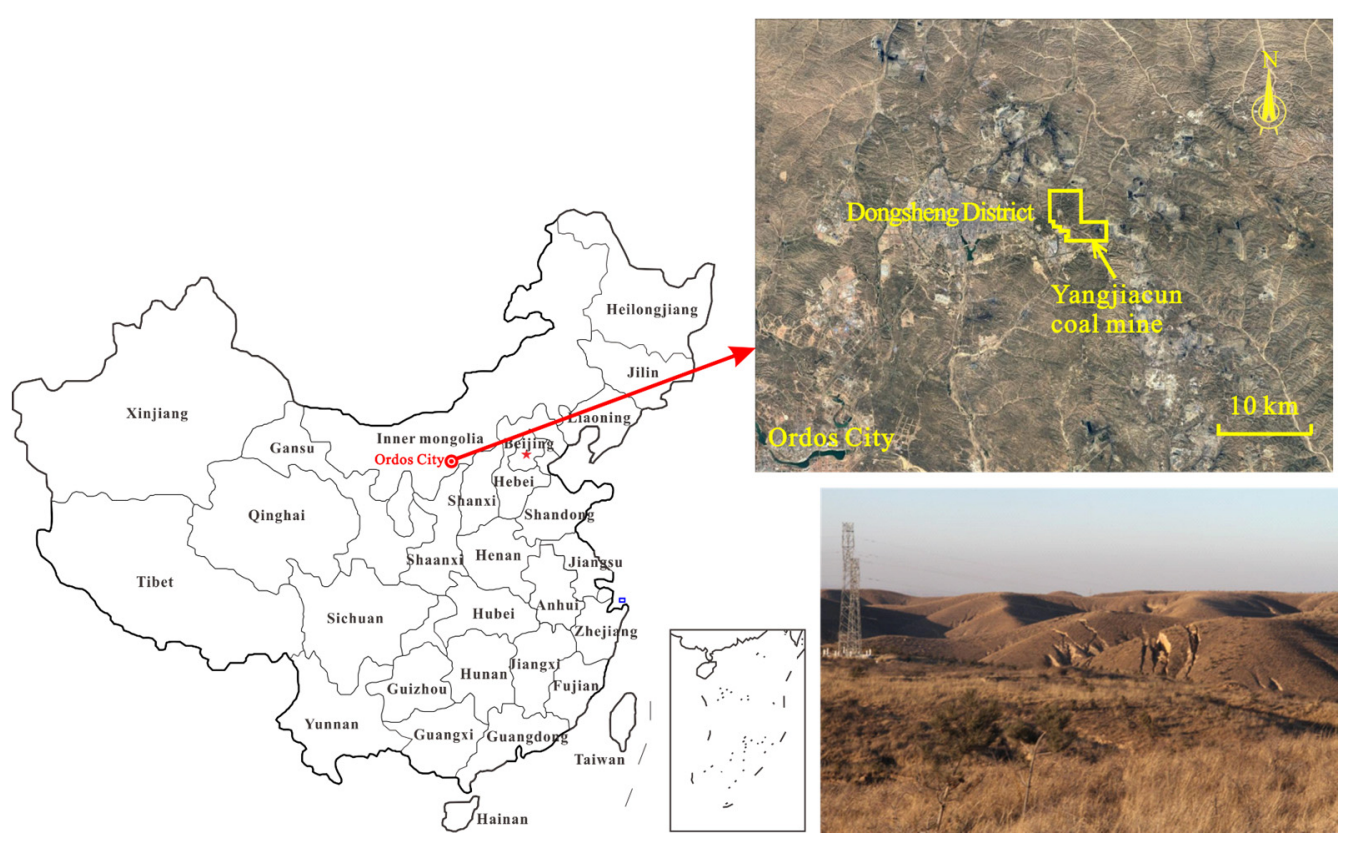

Figure 2. Location of Yangjiacun Coal Mine in Dongsheng Coal Field of Ordos City, inner Mongolia.

\begin{tabular}{|c|c|c|c|c|}
\hline No. & \begin{tabular}{|c|} 
Thickness \\
$(\mathrm{m})$
\end{tabular} & $\begin{array}{l}\text { Depth } \\
\text { (m) }\end{array}$ & $\begin{array}{l}\text { Stratigraphic } \\
\text { column }\end{array}$ & Lithology \\
\hline 1 & 78 & 0 & 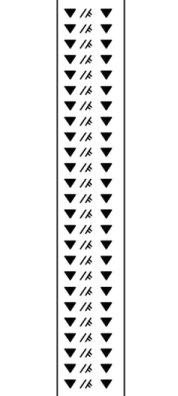 & $\begin{array}{c}\text { Topsoil } \\
\text { Q }\end{array}$ \\
\hline 2 & 25 & 78 & 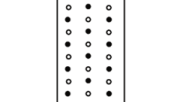 & $\begin{array}{l}\text { Conglomerate sandstone } \\
\qquad \mathrm{K}_{1} \mathrm{zh}\end{array}$ \\
\hline 3 & 17 & 103 & 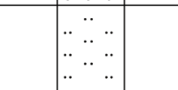 & $\begin{array}{l}\text { Medium sandstone } \\
\mathrm{J}_{2} \mathrm{a}\end{array}$ \\
\hline 4 & 20 & 120 & 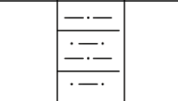 & $\begin{array}{l}\text { Sandy mudstone } \\
\qquad \mathrm{J}_{2} \mathrm{Z}\end{array}$ \\
\hline 5 & 19 & 140 & \begin{tabular}{|l|}
$-\cdot-$ \\
$\cdot-\cdot \cdot$ \\
$\cdot-\cdot$
\end{tabular} & $\begin{array}{l}\text { Sandy mudstone } \\
\mathrm{J}_{1-2} \mathrm{y}^{3}\end{array}$ \\
\hline 6 & 7 & 159 & 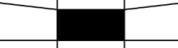 & 2-2 Coal \\
\hline 7 & 46 & 166 & 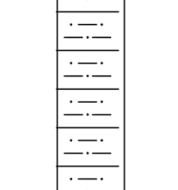 & $\begin{array}{l}\text { Sandy mudstone } \\
\qquad \mathrm{J}_{1-2} \mathrm{y}^{3}\end{array}$ \\
\hline 8 & 5 & 212 & $\frac{-.-}{.-.}$ & 4-1 Coal \\
\hline 9 & 18 & 217 & \begin{tabular}{|l|}
$-\cdot-$ \\
$\dot{-} \cdot \dot{-}$ \\
$\cdot-\cdot$ \\
\end{tabular} & $\begin{array}{c}\text { Sandy mudstone } \\
\mathrm{J}_{1-2} \mathrm{y}^{2}\end{array}$ \\
\hline
\end{tabular}

Figure 3. Stratigraphic section of Yangiacun Coal Mine, according to the borehole data of GJ18 (as marked in Figure 4). 


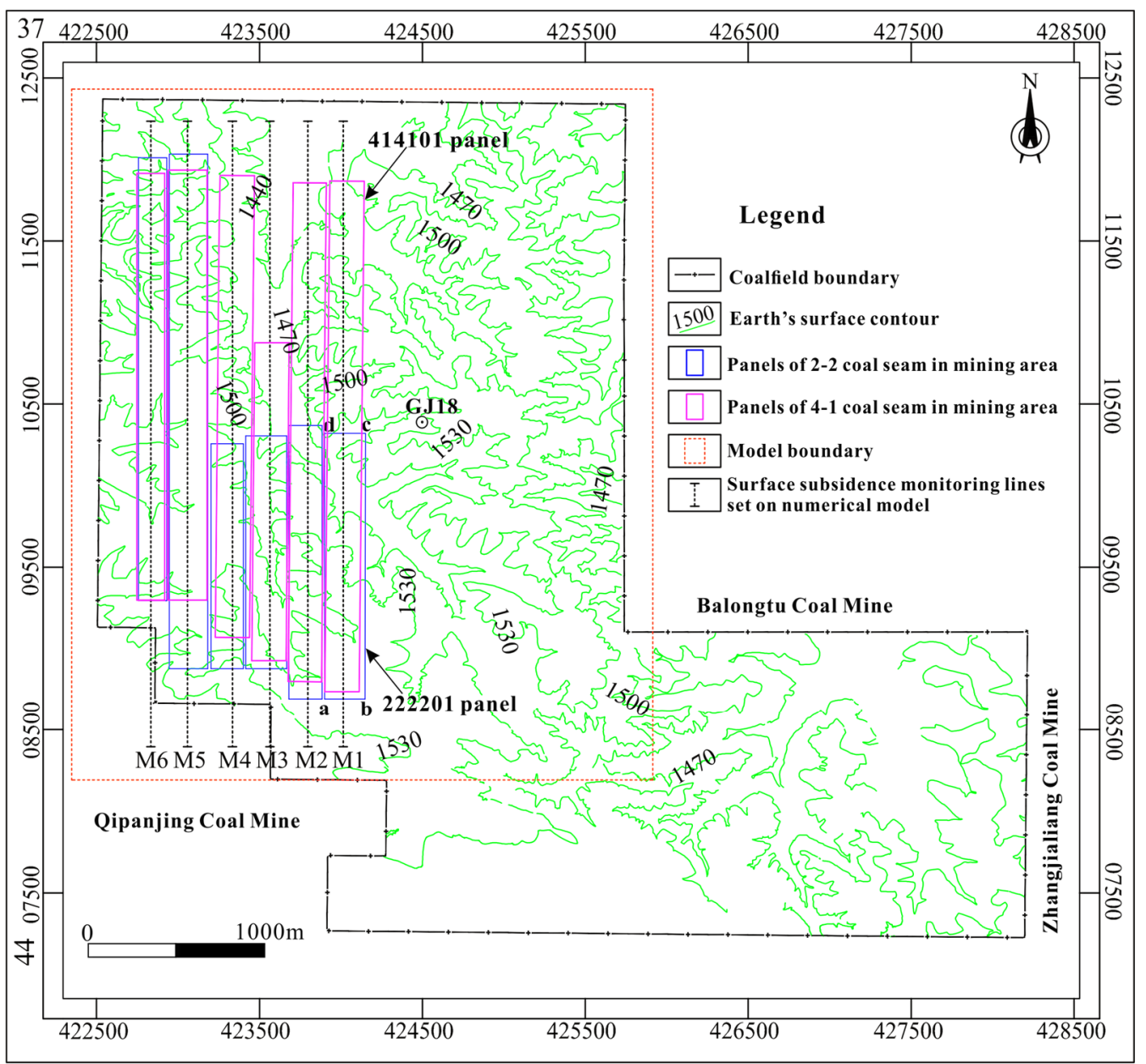

Figure 4. The layout of panels in Yangjiacun Coal Mine and monitoring lines in numerical simulation (line M1 to line M6). Points a, b, c, and d are the boundary points of panel No. 222201. The GPS subsidence monitoring points (as shown in Figure 5) are located on the surface above panel No. 222201.

Table 1. The dimensions of panels in Yangjiacun Coal Mine.

\begin{tabular}{ccccc}
\hline Stratum & Panel & Length $(\mathbf{m})$ & Width $(\mathbf{m})$ & $\begin{array}{c}\text { Mined or Unmined } \\
\text { (By December, 2018) }\end{array}$ \\
\hline \multirow{5}{*}{ 2-2 Coal } & 222201 & 1600 & 240 & Mined \\
& 222202 & 1677 & 200 & Mined \\
& 222203 & 1437 & 250 & Mined \\
& 22204 & 1480 & 200 & Mined \\
& 222205 & 3055 & 240 & Mined \\
\hline \multirow{4}{*}{ 4-1 Coal } & 2617 & 170 & Mined \\
& 414101 & 3127 & 212 & Unmined \\
& 414102 & 3056 & 204 & Unmined \\
& 414103 & 1950 & 210 & Unmined \\
& 414105 & 2829 & 211 & Unmined \\
& 414106 & 2637 & 240 & Unmined \\
\hline
\end{tabular}

\subsection{Surface Subsidence Monitoring}

The four control points (JZ01-JZ04, as shown in Figure 5) were set up and monitored with GPS receiver, which were known and stable and reliable away from the surface settlement deformation zone. They were established according to the secondary deformation requirements. The subsidence 
monitoring points are located on the surface above panel No. 222201 (as shown in Figure 4), which were monitored using the total station and level and according to third deformation requirements. The monitoring area is approximately $1600 \mathrm{~m}$ long and $240 \mathrm{~m}$ wide. The monitoring points were established at the end of April 2011. Mining of panel No. 222201 started in May 2011 and ended in May 2012.

Figure 5 shows the layout of the GPS subsidence monitoring points, which constitute two crossed monitoring lines. The monitoring points R1-R110 constitute the R line, while the monitoring points D1-D52 constitute the D line.

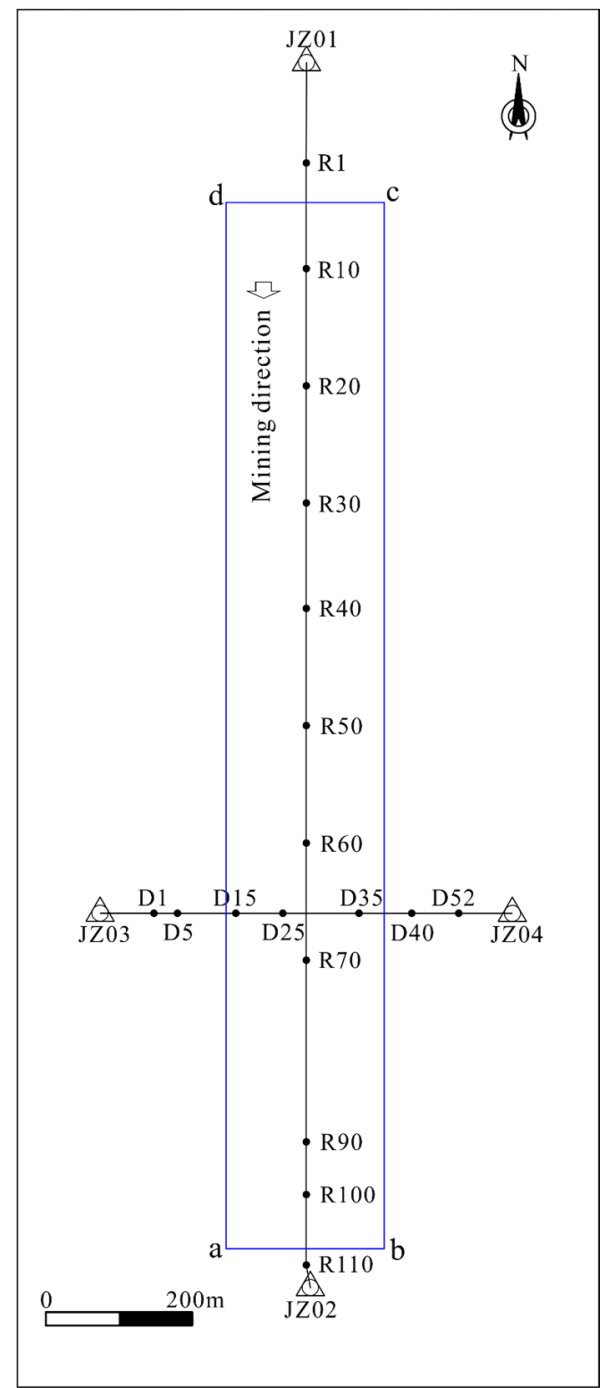

Legend

$\Delta$ the control points $\bullet$ the monitoring points
$\bullet$ the monitoring lines $\square$ No 222201 panel

Figure 5. The layout of subsidence monitoring points on the surface above panel No. 222201. A total of 110 monitoring points (R1-R110) are arranged along the mining direction. The distance between two adjacent monitoring points is $20 \mathrm{~m}$ from $\mathrm{R} 1$ to $\mathrm{R} 80$ and $10 \mathrm{~m}$ from R80 to R110. A total of 52 monitoring points (D1-D52) are arranged perpendicular to the mining direction, and the distance of two adjacent monitoring points is $10 \mathrm{~m}$.

The subsidence results of representative points on the $\mathrm{R}$ line are presented in Figure 6. The results show that the subsidence development was completed approximately 40 days after the mining was completed. 


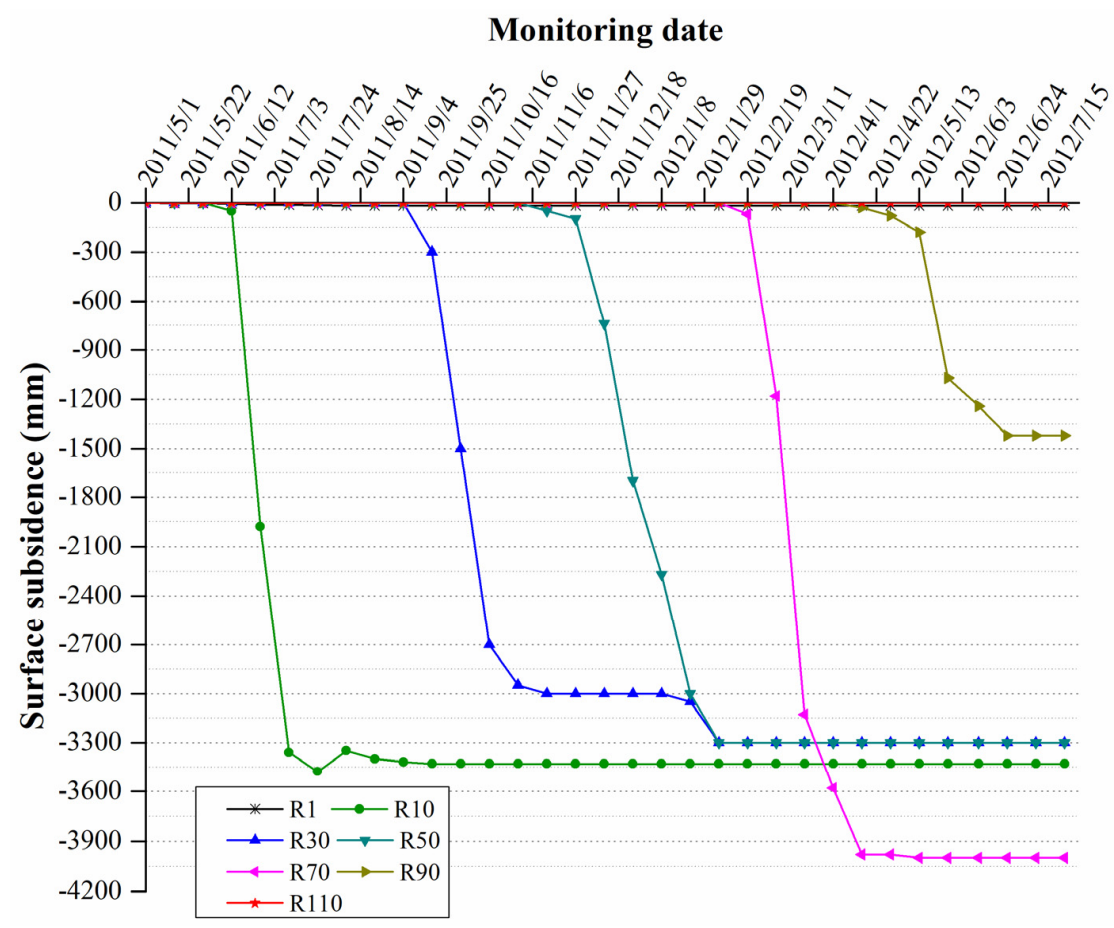

Figure 6. The subsidence results of representative GPS monitoring points on the R line above panel No. 222201. The layout of GPS points is shown in Figure 4.

Figure 7 shows the final subsidence results of the monitoring points on the R line (Figure 5). The following can be concluded:

(1) Because of the small H/M (smaller than 50), the maximum surface subsidence on the $\mathrm{R}$ line reached $4.7 \mathrm{~m}$, which occurred at point $\mathrm{R} 68$.

(2) The subsidence result of the R line shows a U-shaped characteristic, which is similar to the subsidence result of the Huainan coal mine in Anhui Province [33].

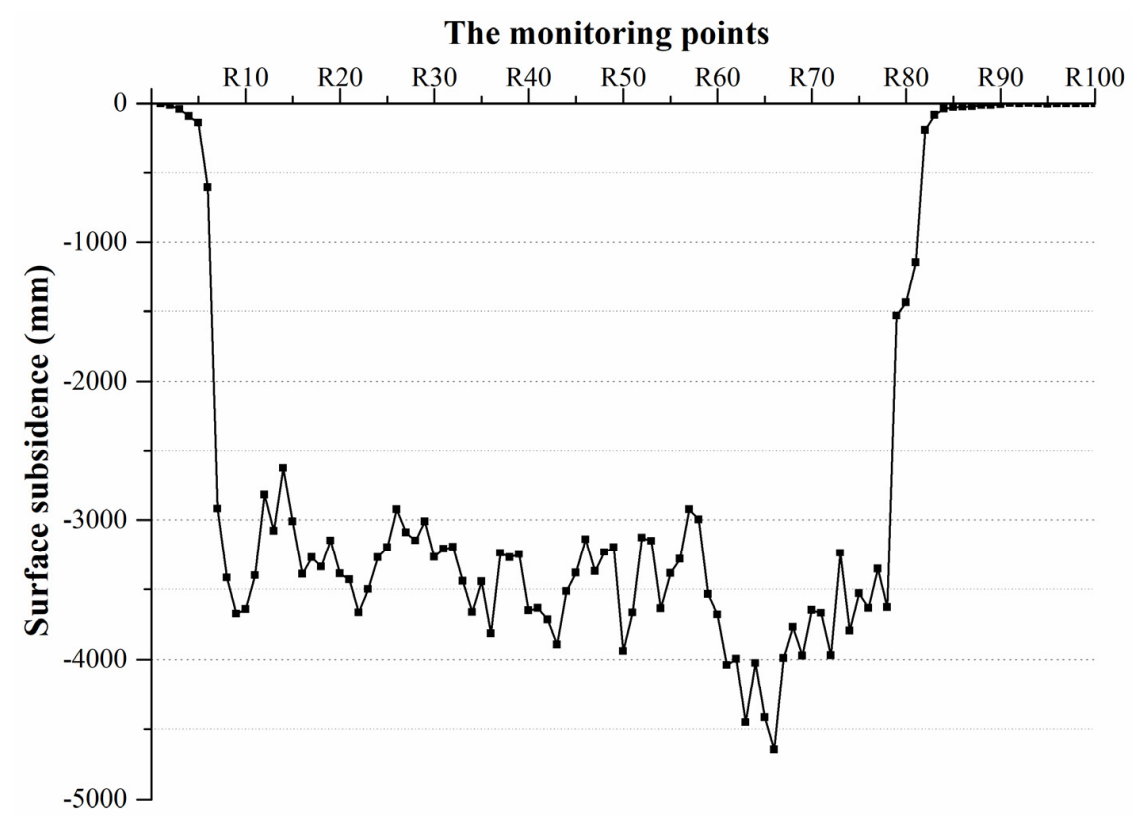

Figure 7. The final subsidence results of the monitoring points on the R line above panel No. 222201 (date: July 15, 2012). 


\subsection{Numerical Model Based on Finite Element Method}

\subsubsection{Model Boundary}

In the numerical model, the boundary is mainly determined by the influenced area of mining. Due to the practical subsidence situation, the length in the $X$ direction (perpendicular to the mining direction) is $3600 \mathrm{~m}$, the length in the $\mathrm{Y}$ direction (parallel to the mining direction) is $4200 \mathrm{~m}$, and the length in the $\mathrm{Z}$ direction (the vertical direction) is $235 \mathrm{~m}$. The numerical model is shown in Figure 8.

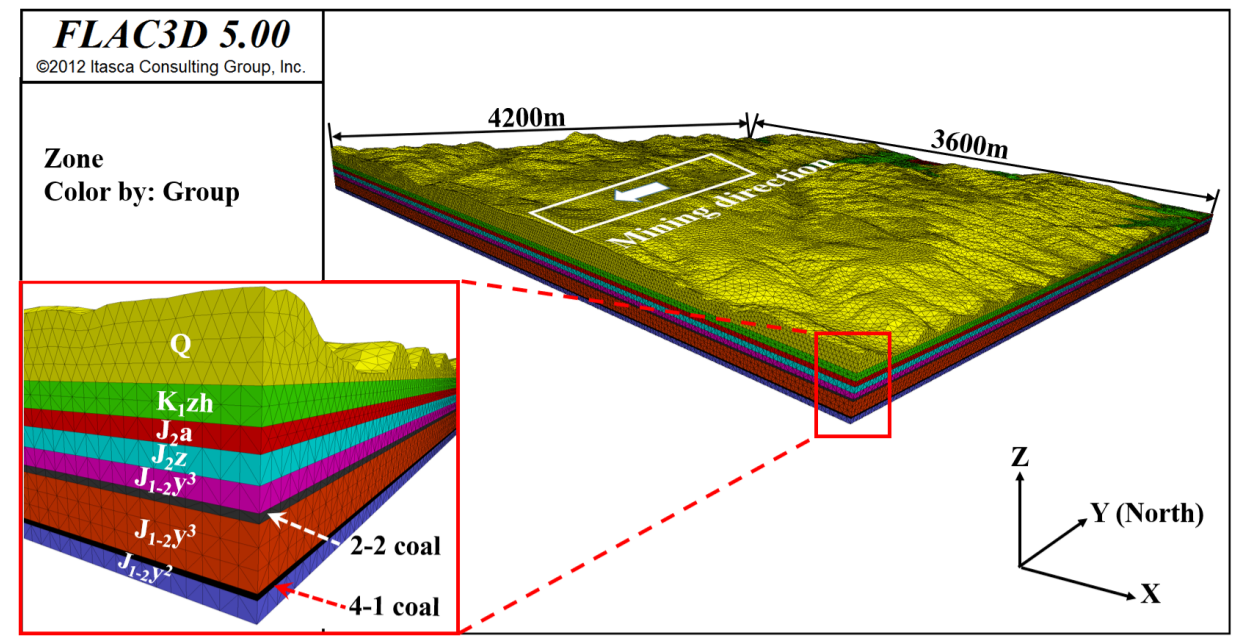

Figure 8. $\mathrm{FLAC}^{3 \mathrm{D}}$ numerical model used for subsidence prediction.

\subsubsection{Mesh Generation}

Considering the accuracy requirement and computational efficiency, a mesh model was built with actual size. In this study, we focused on the surface subsidence in the mining area. Therefore, the element had a smaller size in order to improve the accuracy. The mesh was generated according to the following principle: in the vertical direction, the closer the element is to the surface, the smaller the element size is.

The element size is $8 \mathrm{~m}$ in the horizontal direction and 10 to $14 \mathrm{~m}$ in the vertical direction. This model includes 3,303,784 nodes and 11,204,578 elements, as shown in Figure 8. The mesh model has sufficient accuracy and acceptable computational efficiency.

\subsubsection{The Constitutive Mechanical Model and Yield Criterion}

The incremental elastoplastic constitutive model and the Mohr-Coulomb criterion with tension cutoff are adopted in this study. The failure conditions of the element were described as follows:

When the element is compressive:

$$
\sigma_{1}-\frac{1+\sin \varphi}{1-\sin \varphi} \sigma_{3}+2 c \sqrt{\frac{1+\sin \varphi}{1-\sin \varphi}}=0
$$

When the element is tensile:

$$
\sigma_{1}-\sigma_{\mathrm{t}}=0
$$

where $\sigma_{1}, \sigma_{2}$ and $\sigma_{3}$ are the principle stress, respectively; $\varphi$ is the internal friction angle; $c$ is the cohesion; $\sigma_{\mathrm{t}}$ is the tensile strength.

\subsubsection{Boundary Conditions and the Initial State of Stress}

Sufficiently large model sizes were selected in order to eliminate the boundary effect, namely, the displacement at model boundaries was not affected by the mining activities. The boundary conditions 
of the model were set as follows (see Figure 8): (1) the fixed constraints in the $X$-direction were applied at the eastern and western boundaries of the model; (2) the fixed constraints in the $Y$-direction were applied at the southern and northern boundaries; and (3) the fixed constraint in the Z-direction was applied at the bottom of the model. In addition, no constraint was applied on the upper surface of the model. The displacements at the four lateral boundaries and the bottom boundary were fixed as 0 in the normal direction. The top surface is the free face, the deformation of which was affected by the mining activities. The load of model is composed only of gravity.

\subsection{Mechanical Parameter Inversion}

\subsubsection{Determination of the Initial Mechanical Parameters of Overlying Strata}

The initial mechanical parameters were selected from the data obtained by the laboratory tests of 1271 intact rock samples from Ordos strata according to Li et al. [34]. Based on a large number of experimental studies, Mohammad et al. [28] and Kulatilake et al. [29] found that the E of rock masses is approximately $47-60 \%$ of the intact rock, and the $\mu$ is approximately $115 \%$ of the intact rock. Therefore, the initial mechanical parameters are degraded in this study, of which $\mathrm{E}$ is reduced by $50 \%$ and $\mu$ is increased by $15 \%$. The initial mechanical parameters of the overlying strata are listed in Table 2.

Table 2. Initial mechanical parameters of overlying strata.

\begin{tabular}{cccccc}
\hline No. & Strata & E (GPa) & $\mu$ & c (MPa) & $\boldsymbol{\varphi}\left(^{\circ}\right)$ \\
\hline 1 & Q & 0.07 & 0.36 & 0.06 & 22.6 \\
2 & K1zh & 0.70 & 0.29 & 5.36 & 35.1 \\
3 & J2a & 0.90 & 0.26 & 8.66 & 23.9 \\
4 & J2z & 1.45 & 0.29 & 15.89 & 23.4 \\
5 & J1-2y3 & 1.57 & 0.22 & 18.96 & 26.1 \\
6 & $2-2$ coal & 1.05 & 0.31 & 19.25 & 24.5 \\
\hline
\end{tabular}

\subsubsection{Selection of the Experimental Factors}

Because 4 parameters (i.e., E, $\mu$, c, and $\varphi$ ) are used in the Mohr-Coulomb yielding criterion and there are 6 overlying strata, 24 factors will be considered in the orthogonal experimental design. This means that the calculation of parameter inversion will be difficult and inefficient. Therefore, the orthogonal experimental design is simplified to improve the feasibility and efficiency.

First, the 4 factors of 6 strata are averaged as $\overline{\mathrm{E}}, \bar{\mu}, \overline{\mathrm{c}}$, and $\bar{\varphi}$. Then, $\mathrm{E}, \mu, \mathrm{c}$, and $\varphi$ of each stratum are divided by $\overline{\mathrm{E}}, \bar{\mu}, \overline{\mathrm{c}}$, and $\bar{\varphi}$, and the results are named $\lambda_{\mathrm{E}^{\prime}}^{\mathrm{i}} \lambda_{\mu}^{\mathrm{i}}, \lambda_{\mathrm{C}^{\prime}}^{\mathrm{i}}$ and $\lambda_{\varphi}^{\mathrm{i}}$, where $i$ represents the sequence number of the stratum. Therefore, the parameters of stratum $i$ can be represented by $\lambda_{\mathrm{E}}^{\mathrm{i}} \overline{\mathrm{E}}, \lambda_{\mu}^{\mathrm{i}} \bar{\mu}, \lambda_{\mathrm{C}}^{\mathrm{i}} \overline{\mathrm{c}}$ and $\lambda_{\varphi}^{\mathrm{i}} \bar{\varphi}$.

Then, choose the $\overline{\mathrm{E}}, \bar{\mu}, \overline{\mathrm{c}}$, and $\bar{\varphi}$ as the new factors, and an orthogonal design table with 4 factors and 5 levels can be established (as shown in Table 3). Finally, the orthogonal experimental design is carried out depending on the orthogonal experimental method, and a design table with 25 schemes is shown in Table 4.

Table 3. Orthogonal experimental design table of overlying strata.

\begin{tabular}{ccccc}
\hline \multirow{2}{*}{ Level } & \multicolumn{4}{c}{ Factor } \\
\cline { 2 - 5 } & $\overline{\mathbf{E}} \mathbf{( G P a )}$ & $\overline{\boldsymbol{\mu}}$ & $\overline{\mathbf{c}} \mathbf{( M P a})$ & $\overline{\boldsymbol{\varphi}}\left({ }^{\circ}\right)$ \\
\hline I & 0.54 & 0.25 & 2.66 & 20.1 \\
II & 0.75 & 0.27 & 7.01 & 23.0 \\
III & 0.96 & 0.29 & 11.36 & 25.9 \\
IV & 1.17 & 0.31 & 15.71 & 28.8 \\
V & 1.38 & 0.33 & 20.06 & 31.7 \\
\hline
\end{tabular}


Table 4. The results table of orthogonal experimental design.

\begin{tabular}{cccccc}
\hline Scheme & $\overline{\mathbf{E}}$ & $\bar{\mu}$ & $\overline{\mathbf{c}}$ & $\overline{\boldsymbol{\varphi}}$ & RASS \\
\hline 1 & I & I & I & I & 1.1611 \\
2 & I & II & II & II & 1.1156 \\
3 & I & III & III & III & 1.0891 \\
4 & I & IV & IV & IV & 1.0811 \\
5 & I & V & V & V & 1.0632 \\
\hline 6 & II & I & II & III & 0.7865 \\
7 & II & II & III & IV & 0.7796 \\
8 & II & III & IV & V & 0.7687 \\
9 & II & IV & V & I & 0.7432 \\
10 & II & V & I & II & 0.7259 \\
\hline 11 & III & I & III & V & 0.6029 \\
12 & III & II & IV & I & 0.5964 \\
13 & III & III & V & II & 0.5913 \\
14 & III & IV & I & III & 0.5651 \\
15 & III & V & II & IV & 0.5547 \\
\hline 16 & IV & I & IV & II & 0.4966 \\
17 & IV & II & V & III & 0.4877 \\
18 & IV & III & I & IV & 0.4762 \\
19 & IV & IV & II & V & 0.4632 \\
20 & IV & V & III & I & 0.4558 \\
\hline 21 & V & I & V & IV & 0.4182 \\
22 & V & II & I & V & 0.4097 \\
23 & V & III & II & I & 0.4013 \\
24 & V & IV & III & II & 0.3958 \\
25 & V & V & IV & III & 0.3871 \\
\hline & & & & &
\end{tabular}

\subsubsection{Data Selection}

A total of GPS monitoring points from R13 to R77 with simulated subsidence greater than $3.0 \mathrm{~m}$ on the $\mathrm{R}$ line (along the mining direction) are selected, as shown in Figure 7.

\subsubsection{Simulation according to the Schemes of Orthogonal Experimental Design}

According to the mechanical parameters (i.e., E, $\mu, \mathrm{c}$, and $\varphi$ ) proposed by the schemes of orthogonal experimental design (Table 3), the RASS can be obtained by simulating the subsidence of panel No. 222201 in the FLAC ${ }^{3 D}$ model. The RASS results are shown in the last column of Table 4.

\subsubsection{Determination of Strata Parameters}

As Table 4 shows, the RASS of scheme 5 is 1.0632 , which is closest to 1 . This means that the inversed strata parameters according to scheme 5 (as listed in Table 5) are the optimal parameters for numerical simulation. Figure 9 shows the subsidence results of monitoring and numerical simulation (by adopting the parameters of Table 5) in panel No. 222201.

Table 5. The optimal mechanical parameters of overlying strata obtained by parameter inversion, according to Scheme 5 of Table 4.

\begin{tabular}{cccccc}
\hline No. & Strata & E (GPa) & $\mu$ & c (MPa) & $\boldsymbol{\varphi}\left({ }^{\circ}\right)$ \\
\hline 1 & Q & 0.02 & 0.35 & 0.06 & 22.6 \\
2 & K1zh & 0.36 & 0.29 & 5.36 & 35.1 \\
3 & J2a & 0.47 & 0.26 & 8.66 & 23.9 \\
4 & J2z & 0.75 & 0.29 & 15.89 & 23.4 \\
5 & J1-2y3 & 0.82 & 0.22 & 18.96 & 26.1 \\
6 & $2-2$ coal & 0.54 & 0.31 & 19.25 & 24.5 \\
\hline
\end{tabular}




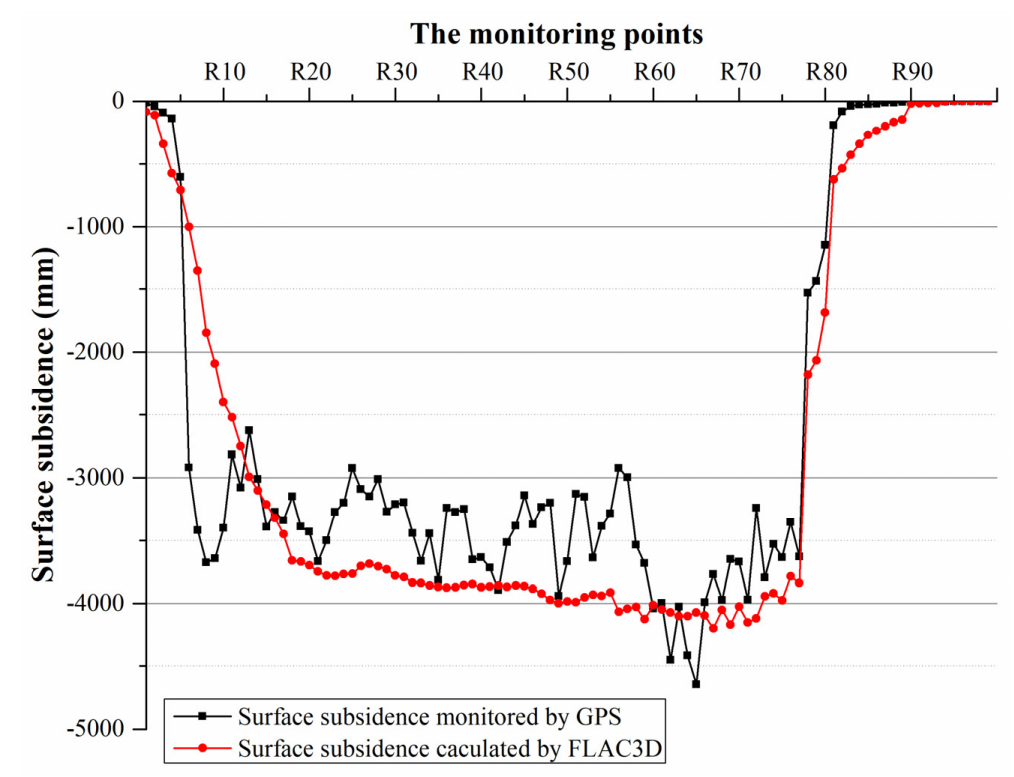

Figure 9. Comparison between the subsidence results of monitoring and FLAC ${ }^{3 \mathrm{D}}$ simulation (by adopting the parameters of Table 5) in panel No. 222201.

\subsection{Prediction in Two-Seam Subsidence}

\subsubsection{Layout of Subsidence Monitoring Points in Numerical Simulation}

The 2-2 and 4-1 coal seams use the same surface subsidence monitoring lines (as shown in Figure 3). A total of 6 monitoring lines (M1-M6) are set up in the numerical model. Each monitoring line has 190 monitoring points, and the distance of adjacent monitoring points is $20 \mathrm{~m}$. The $S$ consists of $S_{1}$ and $S_{2}$, so it can be calculated as $\mathrm{S}=\mathrm{S}_{1}+\mathrm{S}_{2}$.

\subsubsection{Prediction of Subsidence Induced by Upper-Seam Mining $\left(\mathrm{S}_{1}\right)$}

Figures 10 and 11 show the section of $S_{1}$ contours when the development of $S_{1}$ is completed. As shown in Figure 10, panels No. 222201-222206 are distributed from east to west. The following can be determined:

(1) When the development of $S_{1}$ is completed, the maximum $S_{1}$ of each panel is relatively large, which ranges from 2.0 to $5.1 \mathrm{~m}$, and the maximum $\mathrm{S}_{1}$ occurs in panel No. 222203.

(2) The maximum $S_{1}$ of each panel occurs in the central part of the roof. Furthermore, the subsidence is smaller approaching the ground and greater approaching the roofs of the panels.

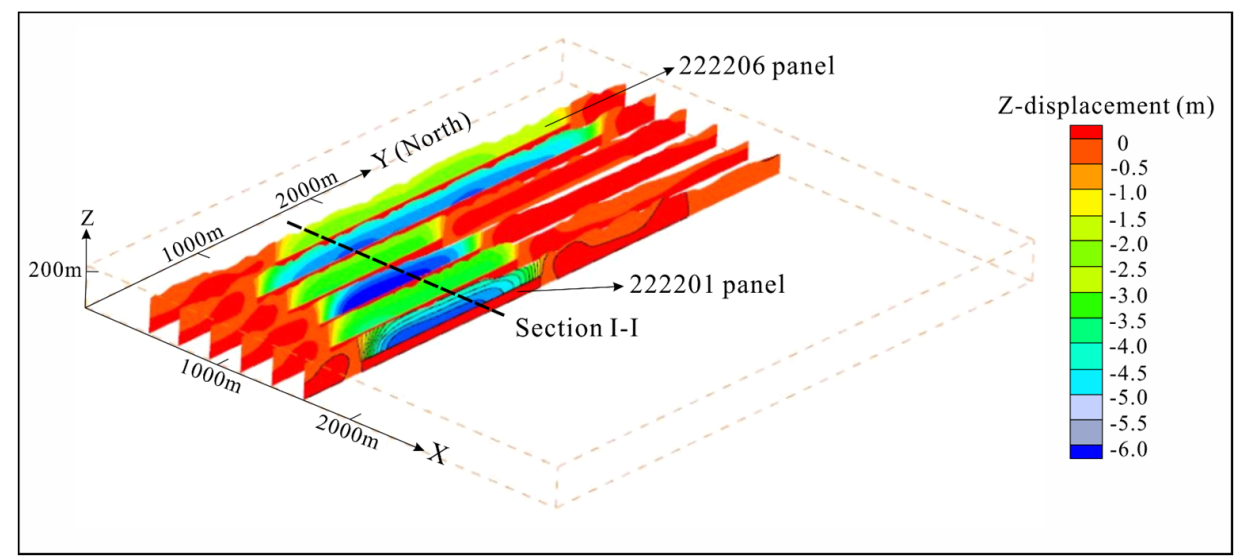

Figure 10. The longitudinal section (along the mining direction) of the $S_{1}$ contour of 6 panels. 


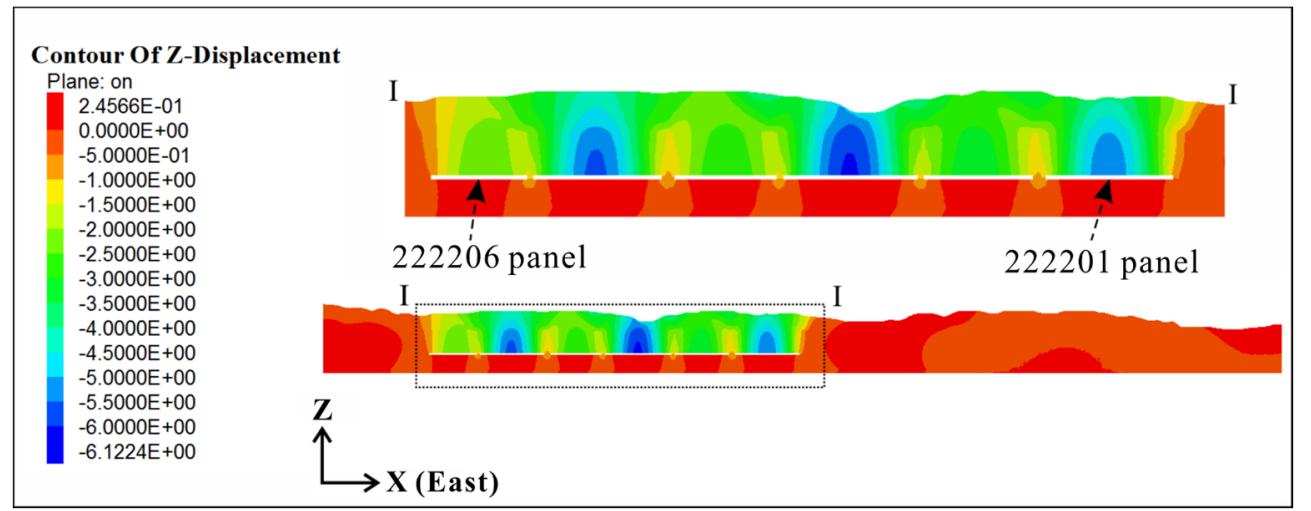

Figure 11. The transverse section (across the mining direction) of the $S_{1}$ contour (section I-I is shown in Figure 9).

\subsubsection{Prediction of Subsidence Induced by the Upper-Seam Mining $\left(\mathrm{S}_{2}\right)$}

Figure 12 shows the transverse section of the $S_{2}$ contour. The maximum $S_{2}$ occurs in panel No. 222203. Figure 13 shows the simulation results of 6 subsidence monitoring lines, including $S_{1}, S_{2}$ and $\mathrm{S}$, which illustrates the following:

(1) The $S$ of line M3 is maximal (11.6 m), which is approximately 2-4 times larger than the $S$ in other lines.

(2) For the subsidence of lines $\mathrm{M} 3$ and $\mathrm{M} 4$, the $\mathrm{S}_{1}$ is approximately as large as $\mathrm{S}_{2}$. For the subsidence of lines M1, M2, M5 and M6, $S_{1}$ is approximately twice as large as $S_{2}$.

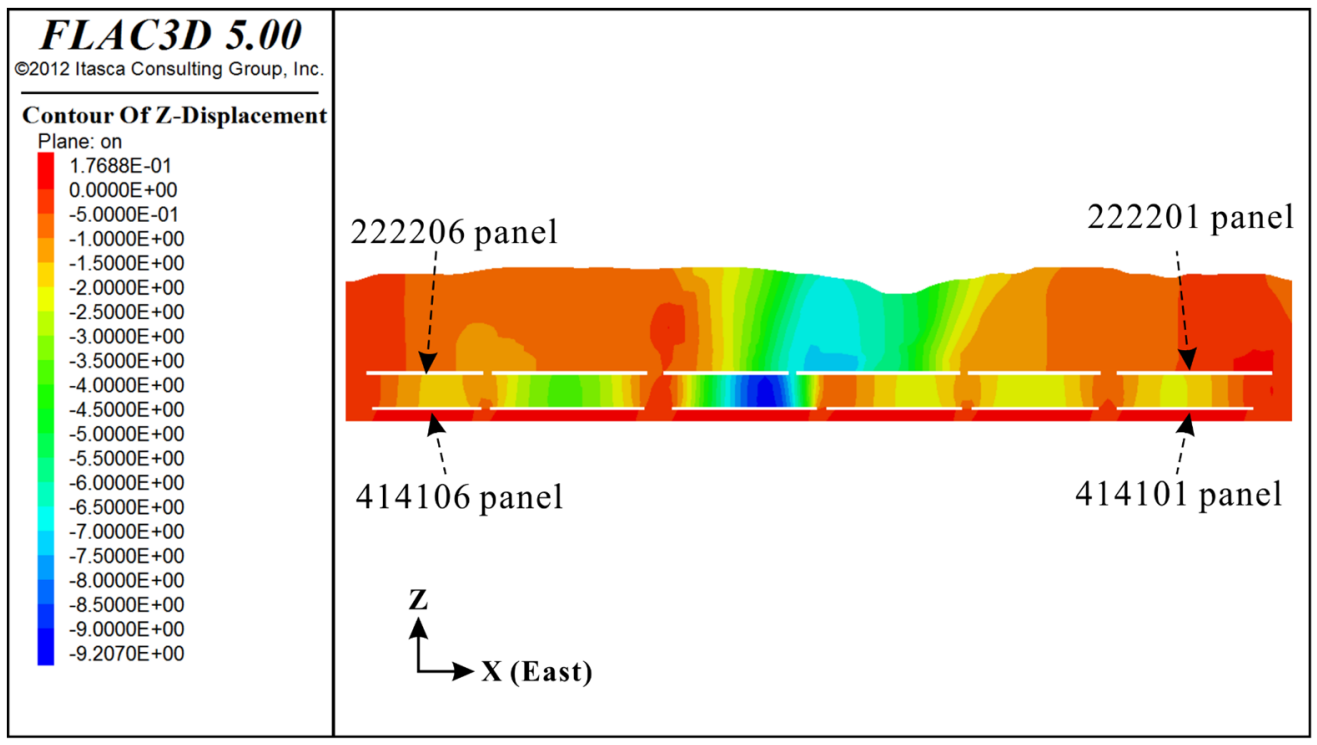

Figure 12. The transverse section of the $S_{2}$ contour (section I-I is shown in Figure 9). 


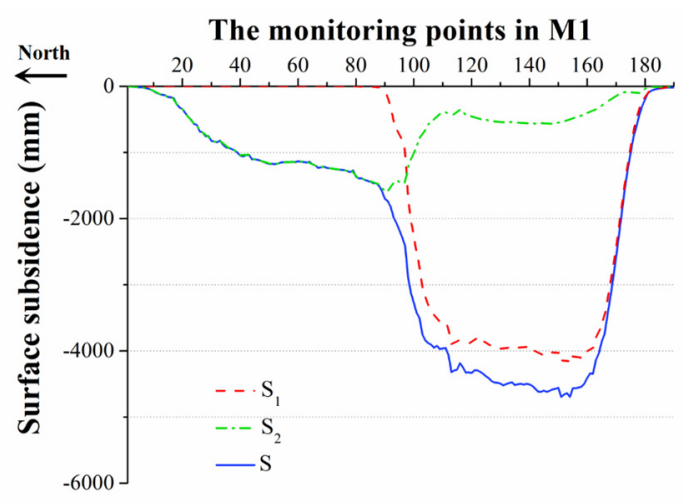

(a)

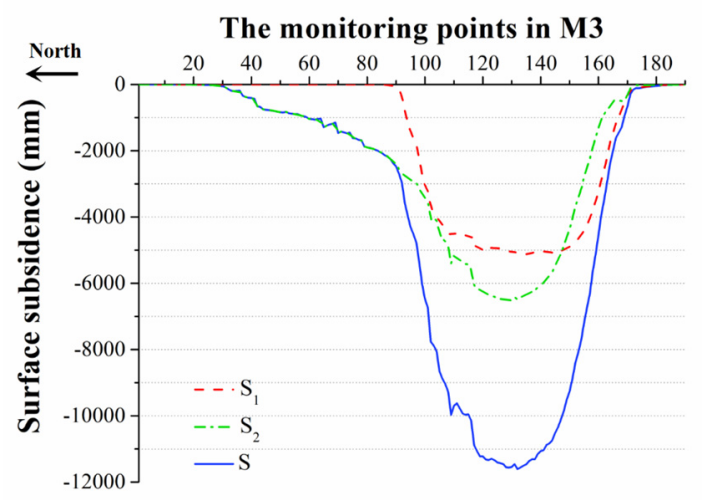

(c)

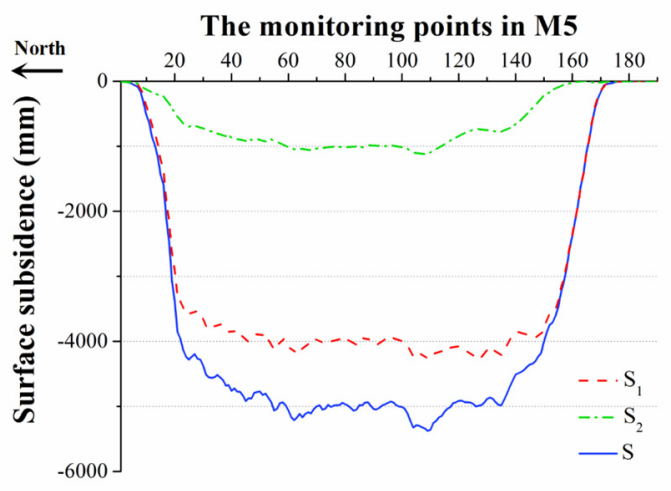

(e)

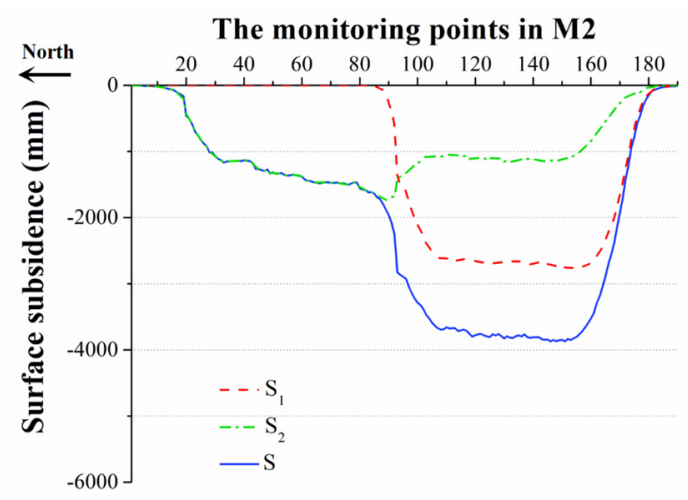

(b)

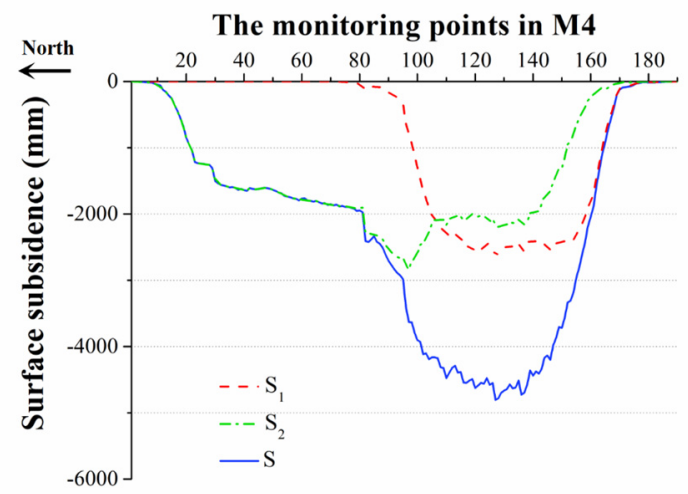

(d)

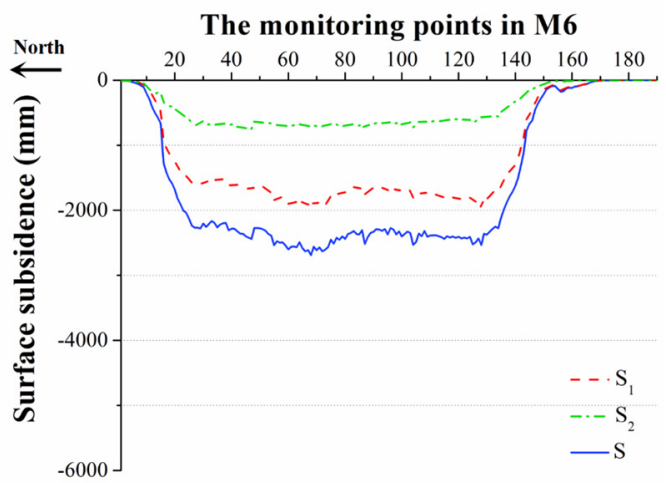

(f)

Figure 13. Results of surface subsidence by FLAC ${ }^{3 \mathrm{D}}$ numerical simulation (M1-M6 are the monitoring lines shown in Figure 3). The dashed lines are $S_{1}$. The dotted lines are $S_{2}$. The solid lines are $S$.

\section{Analysis and Discussion}

\subsection{Effect Factors of Surface Subsidence}

According to Table 6 and Figures 10-12, H/M, and adjacent mining have a significant effect on the surface subsidence of two-seam mining.

(1) $\mathrm{H} / \mathrm{M}$ has an effect on two-seam mining subsidence. There is a significant trend of negative correlations between the surface subsidence and H/M [32,35] (see Figure 14). The stress redistribution would be induced by the mining activities, which is the major reason that cause surface subsidence. In general, the closer to the free face the zone is, the more severe the disturbance is, namely, the 
larger the displacement that would be induced. Therefore, a large $\mathrm{H} / \mathrm{M}$ would generate a small displacement. In this study, since the realistic topography configuration is considered in this numerical model (as shown in Figure 4, Figure 8), $\mathrm{H} / \mathrm{M}$ will change in different locations. The $\mathrm{S}_{1 \max }$, the $\mathrm{S}_{2 \max }$ and the $S_{\max }$ of 6 monitoring lines (M1-M6) also show negative correlations with the mean value of $\mathrm{H} / \mathrm{M}$ in each panel (as shown in Table 6), which is consistent with existing research results.

(2) The effect of adjacent mining is apparent in two-seam mining. The main reason is the superposition effects of different mining activities. The sizes of the disturbance area induced by mining activities are larger than that of the mining zone. When the adjacent mining activities proceed, stress redistribution and displacement will take place, thus inducing greater displacement. In this study, the monitoring lines M1 and M5 have similar $\mathrm{H} / \mathrm{M}$ both in the upper panels and lower panels, the $\mathrm{S}_{1 \max }$ are roughly the same, but the $S_{\max }$ of line M1 is only $87 \%$ of the $S_{\max }$ of line M5. The reason is that the subsidence of line M5 is influenced by the adjacent mining of panels No. 222204 and No. 222206, but the subsidence of line M1 is only influenced by the adjacent mining of panel No. 222202, as shown in Figures 11 and 12. This difference is hidden in single-seam mining, but it is apparent in two-seam mining because of the repeated mining.

Table 6. Mining thickness, $\mathrm{H} / \mathrm{M}$ and surface subsidence of two-seam mining in 6 monitoring lines.

\begin{tabular}{|c|c|c|c|c|c|c|c|}
\hline \multirow{2}{*}{$\begin{array}{l}\text { Monitoring } \\
\text { Line }\end{array}$} & \multicolumn{3}{|c|}{ The Upper Seam } & \multicolumn{4}{|c|}{ The Lower Seam } \\
\hline & $\begin{array}{c}\text { Mining } \\
\text { Thickness (m) }\end{array}$ & $\mathrm{H} / \mathbf{M}$ & $\mathrm{S}_{1 \max }(\mathrm{m})$ & $\begin{array}{c}\text { Mining } \\
\text { Thickness (m) }\end{array}$ & $\mathbf{H} / \mathbf{M}$ & $\mathrm{S}_{2 \max }(\mathrm{m})$ & $\mathrm{S}_{\max }(\mathrm{m})$ \\
\hline M1 & \multirow{6}{*}{7.0} & 21 & 4.23 & \multirow{6}{*}{5} & 36 & 1.61 & 4.74 \\
\hline M2 & & 24 & 2.82 & & 40 & 1.78 & 3.96 \\
\hline M3 & & 17 & 5.13 & & 31 & 6.53 & 11.62 \\
\hline M4 & & 25 & 2.63 & & 41 & 2.84 & 4.83 \\
\hline M5 & & 22 & 4.34 & & 37 & 1.14 & 5.46 \\
\hline M6 & & 27 & 2.02 & & 43 & 0.78 & 2.72 \\
\hline
\end{tabular}

Note: The H/M in Table 6 is the mean value of each panel. $\mathrm{S}_{1 \max }$ is the maximum subsidence induced by mining the upper seam, $S_{2 \max }$ is the maximum subsidence induced by mining the lower seam, and $S_{\max }$ is the maximum final subsidence.

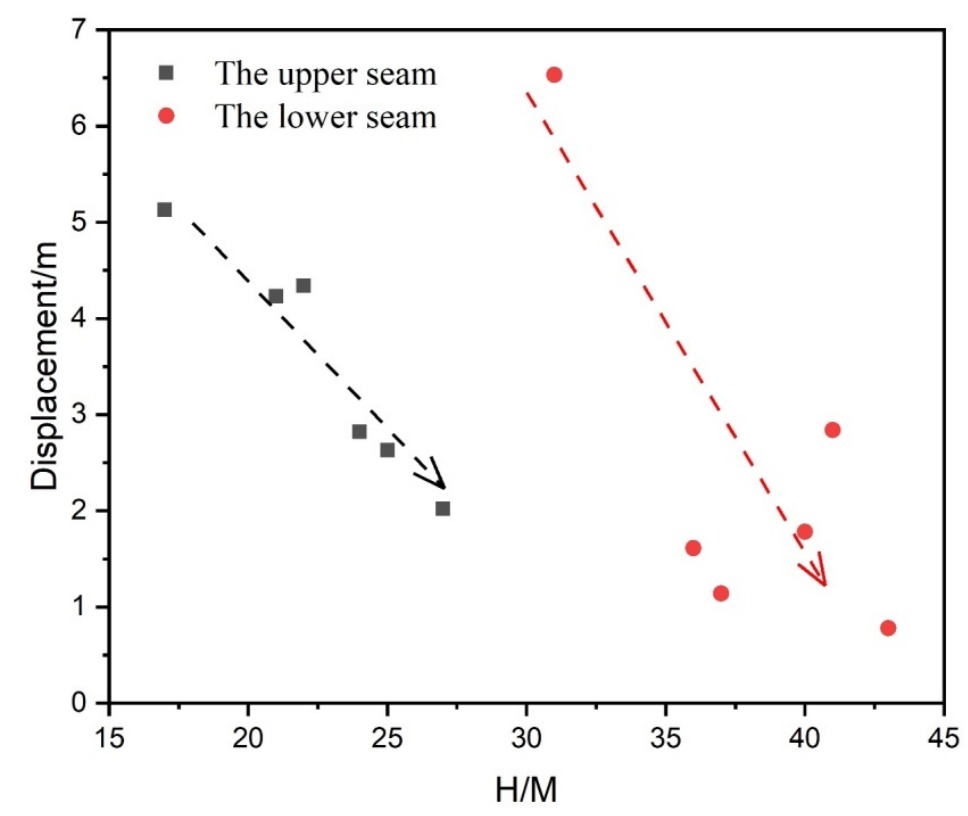

Figure 14. The relationship between $\mathrm{H} / \mathrm{M}$ and subsidence displacement. 


\subsection{Method of Subsidence Prediction in Single-Seam and Multiseam Mining}

This work reported a significative and comprehensive method to predict the subsidence displacement of multiseam mining, which also proposed a valuable reference for analogical engineering. The basic thought of this method is to obtain the accurate parameters of strata according to the existing data and then predict the further deformation. The inverted parameters can describe the mechanical behavior of strata and have highly accurate for subsidence prediction because the initial strata parameters are selected from the data of laboratory tests and inversely refer to the subsidence monitoring. Moreover, the monitoring data of subsidence could be obtained according different measures, including the GPS monitoring in this paper, the interferometric synthetic aperture radar (InSAR) method and so on.

\section{Conclusions}

The methodology proposed in this paper could make a prediction for subsidence in two-seam mining and proposed a significant reference for analogical engineering. The method can be summarized as follows: (1) monitor the surface subsidence of longwall mining, (2) establish a 3D model and invert the mechanical parameters of overlying strata based on the monitoring data using orthogonal experimental design and numerical simulation, (3) calculate the two-seam subsidence by numerical simulation.

Moreover, this method was applied to study a two-seam case in the Yangjiacun Coal Mine of the Dongsheng Coal Field in Inner Mongolia. The results show that the subsidence and H/M show roughly tendency of negative correlations in two-seam mining and adjacent mining have an effect on the subsidence of two-seam mining.

Supplementary Materials: The following are available online at http://www.mdpi.com/1996-1073/12/16/3139/s1.

Author Contributions: This paper was completed under the guidance of B.Z., L.X. and J.Y. established the numerical model, analyzed the results and completed the writing of most of the manuscripts. Z.Z. contributed to the concept, thought and organization of the study. Writing-review; editing, N.X.

Funding: This work was funded by the National Natural Science Foundation of China (No. 41572301, No. 40902086) and the Fundamental Research Funds for the Central Universities of China (No. 2-65-2018-108).

Acknowledgments: The authors would like to thank the reviewers for their constructive comments, which improved the paper.

Conflicts of Interest: The authors declare no conflict of interest.

\section{References}

1. Feng, X.W.; Zhang, N.; Gong, L.Y.; Xue, F.; Zheng, X.G. Application of a backfilling method in coal mining to realise an ecologically sensitive "Black Gold" industry. Energies 2015, 8, 3628-3639. [CrossRef]

2. Sun, Q.; Zhang, J.X.; Zhang, Q.; Zhao, X. Analysis and prevention of geo-environmental hazards with high-intensive coal mining: A case study in China's western eco-environment frangible area. Energies 2017, 10, 786. [CrossRef]

3. Nie, L.; Zhang, M.; Jian, H.Q. Analysis of surface subsidence mechanism and regularity under the influence of seism and fault. Nat. Hazards 2013, 66, 773-780. [CrossRef]

4. Salmi, E.F.; Nazem, M.; Karakus, M. Numerical analysis of a large landslide induced by coal mining subsidence. Eng. Geol. 2017, 217, 141-152. [CrossRef]

5. Najjar, Y.; Zaman, M. Surface subsidence prediction by nonlinear finite-element analysis. J. Geotech. Eng. 1993, 119, 1790. [CrossRef]

6. Alejano, L.R.; RamíRez-Oyanguren, P.; Taboada, J. FDM predictive methodology for subsidence due to flat and inclined coal seam mining. Int. J. Rock Mech. Min. 1999, 36, 475-491. [CrossRef]

7. Sheorey, P.R.; Loui, J.P.; Singh, K.B.; Singh, S.K. Ground subsidence observations and a modified influence function method for complete subsidence prediction. Int. J. Rock Mech. Min. 2000, 37, 801-818. [CrossRef]

8. Donnelly, L.J.; De La Cruz, H.; Asmar, I.; Zapata, O.; Perez, J.D. The monitoring and prediction of mining subsidence in the Amaga, Angelopolis, Venecia and Bolombolo Regions, Antioquia, Colombia. Eng. Geol. 2001, 59, 103-114. [CrossRef] 
9. Nicieza, C.G.; Fernandez, M.I.A.; Diaz, A.M.; Vigil, A.E.A. The new three-dimensional subsidence influence function denoted by n-k-g. Int. J. Rock Mech. Min. 2005, 42, 372-387. [CrossRef]

10. Singh, K.B. Pot-hole subsidence in Son-Mahanadi Master Coal Basin. Eng. Geol. 2007, 89, 88-97. [CrossRef]

11. Díaz-Fernández, M.E.; Álvarez-Fernández, M.I.; Álvarez-Vigil, A.E. Computation of influence functions for automatic mining subsidence prediction. Comput. Geosci 2010, 14, 83-103. [CrossRef]

12. Xu, N.X.; Kulatilake, P.H.S.W.; Tian, H.; Wu, X.; Nan, Y.H.; Wei, T. Surface subsidence prediction for the WUTONG mine using a 3-D finite difference method. Comput. Geotech. 2013, 48, 134-145. [CrossRef]

13. Unlu, T.; Akcin, H.; Yilmaz, O. An integrated approach for the prediction of subsidence for coal mining basins. Eng. Geol. 2013, 166, 186-203. [CrossRef]

14. Jung, Y.B.; Song, W.K.; Cheon, D.S.; Lee, D.K.; Park, J.Y. Simple method for the identification of subsidence susceptibility above underground coal mines in Korea. Eng. Geol. 2014, 178, 121-131. [CrossRef]

15. Gao, F.Q.; Stead, D.; Kang, H.P. Numerical simulation of squeezing failure in a coal mine roadway due to mining-induced stresses. Rock Mech. Rock Eng. 2015, 48, 1635-1645. [CrossRef]

16. Thongprapha, T.; Fuenkajorn, K.; Daemen, J.J.K. Study of surface subsidence above an underground opening using a trap door apparatus. Tunn. Undergr. Space Technol. 2015, 46, 94-103. [CrossRef]

17. Xu, N.X.; Zhang, J.Y.; Tian, H.; Mei, G.; Ge, Q. Discrete element modeling of strata and surface movement induced by mining under open-pit final slope. Int. J. Rock Mech. Min. 2016, 88, 61-76. [CrossRef]

18. Suchowerska Iwanec, A.M.; Carter, J.P.; Hambleton, J.P. Geomechanics of subsidence above single and multi-seam coal mining. Chin. J. Rock Mech. Eng. 2016, 8, 304-313. [CrossRef]

19. Adhikary, D.; Khanal, M.; Jayasundara, C.; Rao, B. Deficiencies in 2D simulation: A comparative study of 2D versus 3D simulation of multi-seam longwall mining. Rock Mech. Rock Eng. 2015, 49, 2181-2185. [CrossRef]

20. Huang, Q.X.; Cao, J. Research on coal pillar malposition distance based on coupling control of three-field in shallow buried closely spaced multi-seam mining, China. Energies 2019, 12, 462. [CrossRef]

21. Ghabraie, B.; Ghabraie, K.; Ren, G.; Smith, J.V. Numerical modelling of multistage caving processes: Insights from multi-seam longwall mining-induced subsidence. Int. J. Numer. Anal. Met. 2017, 41, 959-975. [CrossRef]

22. Ren, G.; Li, G.; Kulessa, M. Application of a generalised influence function method for subsidence prediction in multi-seam longwall extraction. Geotech. Geol. Eng. 2014, 32, 1123-1131. [CrossRef]

23. Khanal, M.; Adhikary, D.; Jayasundara, C.; Balusu, R. Numerical study of mine site specific multiseam mining and its impact on surface subsidence and chain pillar stress. Geotech. Geol. Eng. 2016, 34, 217-235. [CrossRef]

24. Zhang, B.; Zhang, L.Z.; Yang, H.L.; Zhang, Z.J.; Tao, J.L. Subsidence prediction and susceptibility zonation for collapse above goaf with thick alluvial cover: A case study of the Yongcheng coalfield, Henan Province, China. Bull. Eng. Geol. Environ. 2016, 75, 1117-1132. [CrossRef]

25. Ghabraie, B.; Ren, G.; Smith, J.V. Characterising the multi-seam subsidence due to varying mining configuration, insights from physical modelling. Int. J. Rock Mech. Min. 2017, 93, 269-279. [CrossRef]

26. Ghabraie, B.; Ren, G.; Barbato, J.; Smith, J.V. A predictive methodology for multi-seam mining induced subsidence. Int. J. Rock Mech. Min. 2017, 93, 280-294. [CrossRef]

27. Hoek, E.; Brown, E.T. Practical estimates of rock mass strength. Int. J. Rock Mech. Min. 1997, 34, 1165-1186. [CrossRef]

28. Mohammad, N.; Reddish, D.J.; Stace, L.R. The relation between in situ and laboratory rock properties used in numerical modelling. Int. J. Rock Mech. Min. 1997, 34, 289-297. [CrossRef]

29. Kulatilake, P.H.S.W.; Park, J.; Um, J.G. Estimation of rock mass strength and deformability in 3-D for a $30 \mathrm{~m}$ cube at a depth of $485 \mathrm{~m}$ at Äspö Hard Rock Laboratory. Geotech. Geol. Eng. 2004, 22, 313. [CrossRef]

30. Kodama, J.; Miyamoto, T.; Kawasaki, S.; Fujii, Y.; Kaneko, K.; Hagan, P. Estimation of regional stress state and Young's modulus by back analysis of mining-induced deformation. Int. J. Rock Mech. Min. 2013, 63, 1-11. [CrossRef]

31. Janin, J.P.; Dias, D.; Emeriault, F.; Kastner, R.; Le Bissonnais, H.; Guilloux, A. numerical back-analysis of the southern Toulon tunnel measurements: A comparison of 3D and 2D approaches. Eng. Geol. 2015, 195, 42-52. [CrossRef]

32. Chen, K.; Zhang, J.Y.; Jia, X.G.; Li, J. Study on surface ground movement law above fully-mechanized mining face in shallow depth seam. Coal Sci. Tech. 2015, 43, 127-170. [CrossRef] 
33. Zhou, D.W.; Wu, K.; Li, L.; Diao, X.P.; Kong, X.S. A new methodology for studying the spreading process of mining subsidence in rock mass and alluvial soil: an example from the Huainan coal mine, China. Bull. Eng. Geol. Environ. 2016, 75, 1067-1087. [CrossRef]

34. Li, H.M.; Li, H.G.; Song, G.J.; Wang, K.L. Physical and mechanical properties of the coal-bearing strata rock in Shendong coal field. J. China Coal Soc. 2016, 41, 2661-2671. [CrossRef]

35. He, G.Q.; Yang, L.; Ling, G.D.; Jia, C.F.; Hong, D. Mining Subsidence Theory; China University of Mining and Technology Press: Xuzhou, China, 1991; p. 79. ISBN 7810214497.

(C) 2019 by the authors. Licensee MDPI, Basel, Switzerland. This article is an open access article distributed under the terms and conditions of the Creative Commons Attribution (CC BY) license (http://creativecommons.org/licenses/by/4.0/). 